\title{
THE CEREBRAL VASCULAR RESPONSE TO REDUCTION IN ARTERIAL CARBON DIOXIDE TENSION *
}

\author{
By ALBERT J. WASSERMAN AND JOHN L. PATTERSON, JR. \\ (From the Department of Medicine, Medical College of Virginia, Richmond, Va.)
}

(Submitted for publication February 2, 1961; accepted February 27, 1961)

Since the work of Kety and Schmidt in 1948 (1), it has been apparent that the carbon dioxide tension of the arterial blood is an important factor in the control of cerebral blood flow in man. These workers showed that hyperventilation, with its consequent hypocapnia and alkalosis, is associated with a decrease in cerebral blood flow and an increase in cerebral vascular resistance. Conversely, hypercapnia, induced by inhalation of carbon dioxide, resulted in an increase in cerebral blood flow and a decrease in cerebral vascular resistance. Only the effects of marked alterations in carbon dioxide tension were reported. Since this work appeared, it has become evident that the cerebral vessels are commonly confronted with, and can respond to, smaller changes in carbon dioxide tension. Previous studies in this laboratory (2) have defined the threshold and pattern of response of the cerebral vessels to induced hypercapnia. Observations on the cerebral vascular response to reduction in arterial carbon dioxide tension over a wide range, with special emphasis upon the early phases of this response, form the basis of the present report.

\section{METHODS}

The subjects were normal adult male volunteers with a mean age of 38 and an age range of 30 to 50 years. All studies were done in the forenoon with subjects in the supine position.

I. Cerebral blood flow was measured in six subjects by the nitrous oxide technique of Kety and Schmidt (3) as modified by this laboratory (4). The subjects breathed the gas for 10 minutes. Paired blood samples for $\mathrm{N}_{2} \mathrm{O}$, $\mathrm{O}_{2}$ and $\mathrm{CO}_{2}$ contents and $\mathrm{pH}$ were withdrawn from indwelling needles placed percutaneously in the brachial artery and in the internal jugular bulb after local anes-

* Supported by a grant (NIH H-3361) from the National Institutes of Health, Bethesda, Md., and in part by Office of Naval Research Contract Nonr 1134(01). Presented in part before the Southern Society for Clinical Research, New Orleans, I.a., January, 1959 and as part of a presentation before the American College of Physicians, San Francisco, Calif., April, 1960. thesia. After a control resting cerebral blood flow determination, the subjects hyperventilated for 15 minutes, and the second cerebral blood flow determination was carried out during the last 10 of these 15 minutes. Pulmonary minute ventilation was measured by pneumographs on the lower thorax and epigastrium calibrated on the subject against a spirometer at the time of the experiment, or by a recording Tissot gasometer collecting the expired air. Arterial pressure was recorded with a Statham $\mathrm{P}^{23 \mathrm{D}_{\mathrm{b}}}$ or $\mathrm{P} 23 \mathrm{G}$ strain gauge and a Sanborn Polyviso recorder from the indwelling brachial arterial needle. Mean pressures were obtained by electronic integration or by adding one-third of the pulse pressure to the diastolic pressure.

The $\mathrm{N}_{2} \mathrm{O}$ content of the blood was determined by the method of Kety and Schmidt with slight modifications (4). The $\mathrm{O}_{2}$ and $\mathrm{CO}_{2}$ contents of arterial and jugular venous blood were determined by the gasometric technique of Peters and Van Slyke (5) as modified for the presence of $\mathrm{N}_{2} \mathrm{O}$ by Kety and Schmidt (3). Arterial $\mathrm{pH}$ was measured with a Cambridge model $\mathrm{R} \mathrm{pH}$ meter with appropriate corrections to body temperature (6). $\mathrm{CO}_{2}$ tensions were obtained from the $\mathrm{pH}, \mathrm{CO}_{2}$ content and hematocrit by the nomogram of Singer and Hastings (7).

The cerebral oxygen consumption was calculated as the product of cerebral blood flow and the cerebral arteriovenous difference for oxygen, and the cerebral vascular resistance was calculated by dividing the mean arterial pressure by the cerebral blood flow.

II. The series of experiments described above established that cerebral oxygen consumption was not altered by voluntary hyperventilation (see Results, I). Since, by the Fick equation, cerebral oxygen consumption is equal to the cerebral blood flow times the arteriovenous oxygen difference, and since cerebral oxygen consumption was unaltered by hyperventilation, it follows that cerebral blood flow is proportional to the reciprocal of the arteriovenous oxygen difference, or $\mathrm{CMR}_{\mathrm{O}_{2}}=\mathrm{CBF} \times$ $(\mathrm{A}-\mathrm{V})_{\mathrm{O}_{2}}$ or $\mathrm{CBF}=\mathrm{CMR}_{\mathrm{O}_{2}} /(\mathrm{A}-\mathrm{V})_{\mathrm{O}_{2}}$, but $\mathrm{CMR}_{\mathrm{O}_{2}}=\mathrm{K}$. Thus $\mathrm{CBF} \propto 1 /(\mathrm{A}-\mathrm{V})_{\mathrm{O}_{2}}$.

The percentage change in cerebral blood flow may then be calculated as the experimental $1 /(\mathrm{A}-\mathrm{V})_{\mathrm{O}_{2}}$ divided by the control $1 /(A-V)_{0_{2}}$. Since $(A-V)_{0_{2}}$ and percentage $\mathrm{O}_{2}$ saturation are linearly related, the $(\mathrm{A}-\mathrm{V})_{\mathrm{O}_{2}}$ may be expressed as percentage $\mathrm{O}_{2}$ saturation rather than converted into difference in $\mathrm{O}_{2}$ content expressed as volumes per cent. In the second series of experiments, 11 subjects were studied on 19 separate occasions, by means of brachial arterial and internal jugular venous oxygen saturations, determined oximetrically by drawing blood 
through 2 Waters oximeter cuvets with a syringe-pump. Readings were taken from double-scale oximeter galvanometers. Repeatedly in this laboratory it has been shown that a single individual can accurately read 2 double-scale galvanometers equipped with transmittance scales at a rate greater than 4 times per minute. Optical density scales have been found to be more difficult to read rapidly with accuracy. The readings were recorded by a second individual, who also called the time for the next reading. After control arterial and venous oxygen saturations were recorded and control arterial blood samples drawn for $\mathrm{CO}_{2}$ tension and $\mathrm{pH}$, various levels of hyperventilation were maintained by the subjects until the new oximeter readings had stabilized (usually 2 to 3 minutes). At this point arterial blood samples were again drawn. Blood pressure was recorded just before and between the 2 arterial samples by the method described above. The level of hyperventilation was then altered and additional oximeter readings and arterial blood samples were taken. In these experiments, the $\mathrm{CO}_{2}$ tension was determined by the bubble equilibration technique of Riley, Proemmel and Franke (8). Ventilation was measured as described in the preceding section. Alveolar ventilation was calculated, assuming a dead space of $150 \mathrm{ml}$.

Statistical methods. A trial plot was made relating percentage of control cerebral blood flow on the ordinate and decrease in arterial $\mathrm{CO}_{2}$ tension on the abscissa. The mean values of percentage cerebral blood flow and $\mathrm{CO}_{2}$ tension for each $2.5 \mathrm{~mm} \mathrm{Hg}$ decrease in $\mathrm{CO}_{2}$ tension were then calculated and plotted (shown as open circles in Figure 1) and a curve was visually fitted to these mean points. A flattening out of the curve occurred at larger decreases in $\mathrm{CO}_{2}$ tension, suggesting a logarithmic relationship. In addition, trial plots of the data from individual subjects on a given day on semilogarithmic paper also suggested a general logarithmic relation with a threshold as expressed by Equation 1:

$$
y=a+b x+e
$$

where $y=\mathrm{CBF}$ expressed as per cent of control, $a=y$ intercept, $b=$ slope which measures individual responsiveness of $\mathrm{CBF}$ to $x, x=\log \left(-\Delta \mathrm{P}_{\mathrm{CO}_{2}}\right)$ and $e=\mathrm{a}$ random component representing physiological variation from moment to moment as well as errors of measurement. This equation was written for mathematical convenience in the following form:

$$
y=m+b(x-\bar{x})+e
$$

where $m=$ mean $\mathrm{CBF}$ value for the individual and $\bar{x}=$ arithmetic mean of $x$ values for the individual. Since the $\bar{x}$ is a mean, the original $a$ is replaced by a mean CBF value or $m$ in Equation 2 .

The threshold value of $\Delta \mathrm{PCO}_{2}$ can be derived from Equation 2 by setting $y=100$ per cent to yield:

$$
100=m+b \log \left(-\Delta \mathrm{PCO}_{2}\right)_{\text {threshold }}-b \bar{x}
$$

Rearranging and dividing by $b$ gives:

$$
\log \left(-\Delta \mathrm{PCO}_{2}\right)_{\text {threshold }}=\bar{x}+\frac{m-100}{b}
$$

Taking the antilog of both sides of the equation yields:

$$
\left(\Delta \mathrm{PCO}_{2}\right)_{\text {threshold }}=-\operatorname{antilog}\left(\bar{x}+\frac{m-100}{b}\right)
$$

Equation 2 was fitted to the data from each individual by the method of least squares, i.e., estimates for $m$ and $b$ were determined so as to minimize the sigma $e^{2}$. The curve for a "typical" subject was defined as that curve given by the mean estimates. The arithmetic means of the individual values for $m$ and $b$ were inserted in Equation 2. The error $(e)$ was dropped to give the typical curve. Approximate confidence limits for the typical curve are easily derived from large-sample theory utilizing the observed variances and covariances of the estimated $m$ 's and $b$ 's. The approximate 95 per cent confidence limits, calculated by standard methods (9), for the estimated typical curve are presented in Table I. We may suppose that the true "typical" curve lies somewhere between these confidence limits (this statement is made with 95 per cent confidence) and the "best guess" as to its exact location is given by the estimated typical curve.

\section{RESULTS}

I. The results of the first series of experiments (Table II) show that, with a mean increase in total minute ventilation of $5 \mathrm{~L}$ per minute and an alveolar ventilation of $2.9 \mathrm{~L}$ per minute, there was a resultant decrease in mean arterial $\mathrm{CO}_{2}$ tension of $6.3 \mathrm{~mm} \mathrm{Hg}$ and a rise of $\mathrm{pH}$ of $0.06 \mathrm{U}$. Associated with these changes there was a mean decrease in cerebral blood flow to 79 per cent of the control level. The cerebral vascular resistance increased significantly while mean arterial blood pressure changed insignificantly. On the other hand, the cerebral oxygen consumption was not altered by the act of voluntary hyperventilation.

II. In the second portion of this study, the percentage change in cerebral blood flow was calculated from the change in $(\mathrm{A}-\mathrm{V})_{\mathbf{O}_{2}}$ expressed as per cent of control cerebral blood flow. The individual data are presented in Table III. A

TABLE I

95 Per cent confidence limits for calculated mean curve

\begin{tabular}{ccc}
\hline \hline $\mathrm{PaCO}_{2}$ & Mean CBF & $\begin{array}{l}95 \% \text { Confi- } \\
\text { dence limits }\end{array}$ \\
\hline$m m \mathrm{Hg}$ & $\%$ control & \\
-5 & 84 & $78-89$ \\
-10 & 75 & $70-81$ \\
-15 & 70 & $63-77$ \\
-20 & 66 & $58-75$ \\
-25 & 63.7 & $53-74$ \\
\hline
\end{tabular}


TABLE II

Cerebral blood flow, pulmonary ventilation and related functions *

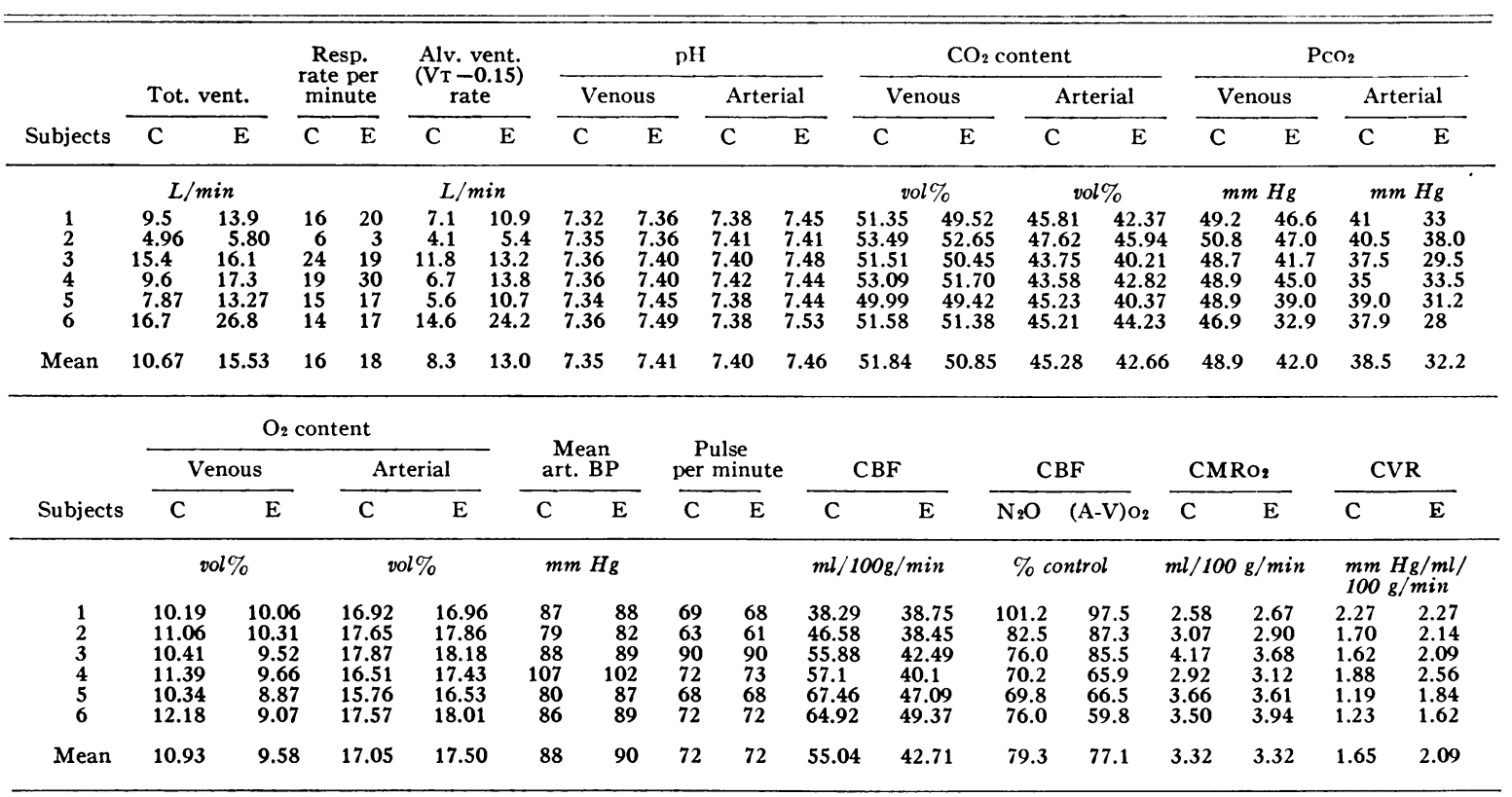

$* \mathrm{C}=$ control period, quiet breathing; $\mathrm{E}=$ period of voluntary hyperventilation; $\mathrm{CBF}=$ cerebral blood flow; $\mathrm{CMRO}_{2}=$ cerebral oxygen consumption; $\mathrm{CVR}=$ cerebral vascular resistance.

graph (Figure 1) was constructed relating per- periments provided 2 to 4 points on the figure. centage of control cerebral blood flow on the ordi- The percentage of control cerebral blood flow was nate to decrease in arterial $\mathrm{CO}_{2}$ tension on the obtained from oximeter data as previously deabscissa. With two exceptions, individual ex- scribed. The plotted change in arterial $\mathrm{CO}_{2}$ ten-

TABLE III

Individual data $\Delta \mathrm{P}_{\mathrm{CO}_{2}}$ vs cerebral blood flow $(\mathrm{CBF})$ as percentage of control determined by arteriovenous oxygen difference

\begin{tabular}{|c|c|c|c|c|c|c|c|c|c|}
\hline \multirow[b]{2}{*}{ Subjects } & \multirow[b]{2}{*}{ Observations } & \multicolumn{4}{|c|}{$\mathrm{PCO}_{2}(\mathrm{~mm} \mathrm{Hg})$} & \multicolumn{4}{|c|}{ CBF (\% control) } \\
\hline & & 1 & 2 & 3 & 4 & 1 & 2 & 3 & 4 \\
\hline 1 & & -14.1 & -27.6 & & & 76.6 & 62.0 & & \\
\hline 2 & & -12.9 & -13.3 & & & 64.0 & 64.5 & & \\
\hline 3 & & -11.0 & -19.0 & & & 73.1 & 67.0 & & \\
\hline 4 & & -19.2 & -20.4 & -23.5 & & 73.2 & 69.8 & 71.4 & \\
\hline 5 & & -21.3 & -21.6 & -21.6 & & 86.1 & 71.6 & 70.5 & \\
\hline 6 & & -2.5 & -12.0 & & & 91.1 & 76.6 & & \\
\hline 7 & & -18.1 & -24.3 & -12.0 & & 79.0 & 60.8 & 88.3 & \\
\hline 8 & & -5.1 & -6.6 & & & 89.8 & 75.9 & & \\
\hline $9^{*}$ & & -5.3 & & & & 96.9 & & & \\
\hline 10 & & -4.1 & +1.2 & -6.0 & & 87.5 & 71.8 & 77.8 & \\
\hline 11 & & -3.1 & -3.5 & -1.9 & -2.3 & 108.0 & 101.0 & 107.0 & 90.9 \\
\hline 12 & & -5.6 & -5.4 & -7.8 & & 82.6 & 78.8 & 91.2 & \\
\hline $13^{*}$ & & -2.9 & & & & 95.3 & & & \\
\hline 14 & & -3.8 & -5.0 & -7.5 & -9.4 & 87.5 & 86.0 & 84.5 & $\begin{array}{l}98.0 \\
98.0\end{array}$ \\
\hline 15 & & -1.1 & -6.6 & -1.5 & -0.0 & 102.1 & 86.7 & 91.5 & 98.0 \\
\hline 16 & & -1.2 & -2.1 & -1.1 & -1.7 & 91.0 & 86.0 & 84.0 & 94.0 \\
\hline 17 & & -15.6 & -9.7 & -15.9 & & 68.7 & 84.2 & 77.0 & \\
\hline 18 & & -18.1 & -12.2 & -21.1 & -23.4 & 59.0 & 61.3 & 55.4 & 61.8 \\
\hline 19 & & -3.6 & -19.6 & -22.0 & & 83.0 & 64.0 & 62.0 & \\
\hline 20 & & -22.0 & -25.0 & -14.7 & -23.1 & 69.3 & 64.6 & 83.4 & 58.2 \\
\hline 21 & & -3.8 & -13.2 & -5.9 & -3.1 & 76.5 & 66.1 & 66.5 & \\
\hline
\end{tabular}

* The statistical method employed (see Methods) precluded the use of the data from these individuals. 


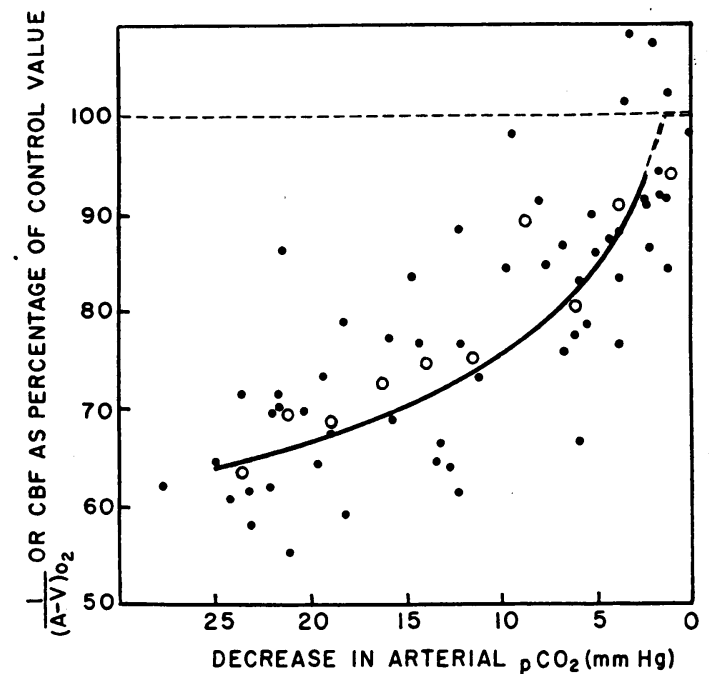

Fig. 1. RELATION OF CONTROL CEREBRAL BLOOD FLOW To INCREASE IN ARTERIAL CARbON DIOXIDE TENSION. On the ordinate is the per cent of control cerebral blood flow as measured by the reciprocal of the arterial-internal jugular venous oxygen difference. On the abscissa is the observed decrease of arterial $\mathrm{CO}_{2}$ tension from the control value (zero). Each solid circle represents a single observation. The average values for cerebral blood flow and $\Delta \mathrm{P}_{\mathrm{CO}_{2}}$ (open circles) for each $2.5 \mathrm{~mm} \mathrm{Hg}$ decrease in $\mathrm{CO}_{2}$ tension are included for reference. The mean curve was determined as described under Statistical Methods.

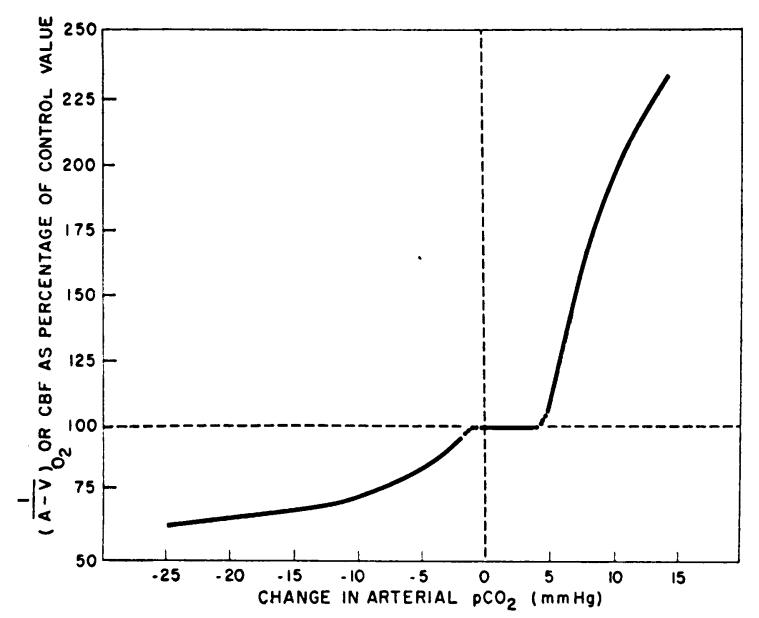

Fig. 2. Cerebral vascular Response to alterations IN ARTERIAL CARBON DIOXIDE TENSION. The ordinate is the percentage of control cerebral blood flow as measured by the reciprocal of the arterial-internal jugular venous oxygen difference. On the abscissa is the observed decrease or increase in arterial $\mathrm{CO}_{2}$ tension. The curve in the lower left quadrant is the mean curve from Figure 1. The curve in the upper right quadrant is derived from previous data from this laboratory (2) to which new data in the higher $\mathrm{CO}_{2}$ ranges were added. sion is the difference between the control and experimental values. The equation for the composite curve, calculated as described under statistical methods was: $y=77.6+(-29.1)(x-$ $0.918)$. A reduction in cerebral blood flow was initiated by a reduction in arterial $\mathrm{CO}_{2}$ tension of only $2 \mathrm{~mm} \mathrm{Hg}$. With further reduction in $\mathrm{CO}_{2}$ tension, the blood flow fell rapidly but with diminishing response per unit change in $\mathrm{CO}_{2}$ tension. A $25 \mathrm{~mm} \mathrm{Hg}$ reduction in arterial $\mathrm{P}_{\mathrm{CO}_{2}}$ was associated with a 34 per cent reduction in cerebral blood flow, and extrapolation of the curve suggests that the vasoconstrictor response would not exceed a value of 40 per cent reduction in cerebral blood flow.

\section{DISCUSSION}

A graph of the full range of cerebral vascular response to alterations in arterial $\mathrm{CO}_{2}$ tension may now be plotted (Figure 2). Using the technique of arterial and internal jugular venous oximetry, 14 points from three subjects breathing various concentrations of $\mathrm{CO}_{2}$ were added to the previously reported data defining the pattern of cerebral vasodilation in response to hypercapnia (2). There is a striking difference in the response to hypocapnia as contrasted with the response to hypercapnia. With decrease in arterial $\mathrm{CO}_{2}$ tension, there appears to be a small (approximately $2 \mathrm{~mm} \mathrm{Hg}$ ) threshold, beyond which further decrease in tension is accompanied by a sharp decline in cerebral blood flow. Since arterial blood pressure changes were negligible during these experiments, the curve of the phenomenon serves as an index of cerebral vasoconstriction. As the arterial $\mathrm{CO}_{2}$ tension declines further, there is a decreasing response per unit of diminution in arterial $\mathrm{CO}_{2}$ tension. In response to hypercapnia, however, after a threshold of about $4.5 \mathrm{~mm} \mathrm{Hg}$, there is a nearly linear response of cerebral blood flow to the increase in arterial $\mathrm{CO}_{2}$ tension throughout the observed range. In one subject cerebral blood flow increased to a peak value 3.5 times control.

Teleologically, the pattern of response is fortunate. Cerebral vasoconstriction with resultant diminution in cerebral blood flow imposes a hazard to vital cerebral function. Studies by Finnerty, Witkin and Fazekas (10) have shown that a reduction in cerebral blood flow of 40 per cent is 
associated with obvious symptoms of cerebral ischemia. It is of interest that the curve of Figure 2, when extrapolated, suggests that the vasoconstrictor response will not exceed this 40 per cent level of reduction in flow. Lesser degrees of reduction of cerebral blood flow are associated with a demonstrable diminution in mental ability (11). The diminishing response of the cerebral vasculature to progressive hypocapnia can be explained by the body's introduction of physiologically antagonistic mechanisms tending to produce vasodilation, which become increasingly powerful as hypocapnia increases. Since the cerebral metabolic rate for $\mathrm{O}_{2}$ remains constant in hyperventilation and since cerebral blood flow decreases significantly, each milliliter of blood traversing the brain will reach the venous end of the capillary after a greater amount of $\mathrm{O}_{2}$ has been extracted and a larger amount of $\mathrm{CO}_{2}$ added. Both hypoxemia and hypercapnia are potent cerebral vasodilators (1). It is not known if endcapillary or venous gas tension changes affect exclusively, or even primarily, the caliber of the vessels which are at the site of these changes. The authors, like many others, have speculated regarding some retrograde mechanism, such as the axon reflex, whereby the arterioles "feel" the effects of changes of gas tensions occurring downstream. To our knowledge no direct evidence is as yet available. In addition, akalosis, induced by hyperventilation, has a moderate vasodilator effect (12). The slight increase in arterial $\mathrm{O}_{2}$ tension which occurs with voluntary hyperventilation during air breathing would have little or no vasoconstrictor effect (1). On the other hand, there is little physiological antagonism to the vasodilator effect of hypercapnia. With hyperventilation induced by inspiring gas mixtures of high $\mathrm{CO}_{2}$ content in air, there is again a slight increase in arterial $\mathrm{O}_{2}$ tension. In addition, the increase in cerebral blood flow with constant cerebral $\mathrm{O}_{2}$ consumption allows the capillary and venous blood to have a further increase in $\mathrm{O}_{2}$ tension but, as already noted, even a marked increase in arterial $\mathrm{O}_{2}$ tension has only a weak vasoconstrictor effect (1). The role of the acidosis which accompanies hypercapnia remains unclear, although it is known that ammonium chloride infusions are associated with weak vasoconstriction in the cerebral vascular bed (12). The shape of this curve, then, is fortunate since serious cerebral hypoxemic symptoms would result if the trend of the early response to hypocapnia persisted; on the other hand, the physiological price to be paid for vasodilation in response to hypercapnia is small.

Since cerebral oxygen consumption remains constant during the extremes of natural sleep and intense mental activity (13), any change in cerebral blood flow must result in a change in the content of $\mathrm{O}_{2}$ and $\mathrm{CO}_{2}$ and in the $\mathrm{pH}$ of the blood in the cerebral capillaries. The intact normal organism, however, maintains arterial $\mathrm{CO}_{2}$ tension within a very narrow range. In view of this stability of arterial $\mathrm{CO}_{2}$ tension and in view of the threshold type of response of the cerebral vasculature to alterations in $\mathrm{CO}_{2}$ tension, it would appear that under normal circumstances little change in cerebral vascular resistance could be expected as a result of fluctuations in arterial $\mathrm{CO}_{2}$ tension. On the other hand, should there be marked changes in perfusion pressure, this mechanism for control of cerebral circulation would become operative. From the Fick equation, and the blood nomogram (7) or the physiological $\mathrm{CO}_{2}$ absorption curve (14) and the venous-arterial $\mathrm{P}_{\mathrm{CO}_{2}}$ increase across the brain, the change in cerebral blood flow required to bring end-capillary and venous $\mathrm{P}_{\mathrm{CO}_{2}}$ to the vasodilator or vasoconstrictor threshold can be calculated. Such calculation shows that a decrease of cerebral blood flow by 30 per cent would cause an elevation in end-capillary and venous cerebral $\mathrm{CO}_{2}$ tension to the level at which initiation of cerebral vasodilation would occur. This would represent a compensatory response to the reduction in cerebral blood flow (2). In addition, the simultaneous reduction in end-capillary and venous $\mathrm{O}_{2}$ tensions would cause further vasodilation. It might be anticipated that the combined action of the $\mathrm{O}_{2}$ and $\mathrm{CO}_{2}$ tension mechanisms would produce protective vasodilation in response to a decrease in cerebral blood flow of significantly less than the 30 per cent required for the $\mathrm{CO}_{2}$ mechanism alone. Conversely, by similar calculations, it can be shown that if cerebral blood flow were to increase by 27 per cent, the decrease in end-capillary and venous $\mathrm{CO}_{2}$ tension resulting from constant cerebral metabolism should initiate the $\mathrm{CO}_{2}$-induced vasoconstriction demonstrated in the previous sections. The function, then, of the $\mathrm{CO}_{2}$ control of cerebral vasculature in re- 
sponse to alterations in cerebral perfusion pressure is not extremely sensitive, but would be protective in cases of marked alterations.

In contrast to the mild influence of $\mathrm{CO}_{2}$ tension in response to alterations in cerebral perfusion is the major role which this mechanism must occupy in primary alterations of arterial $\mathrm{CO}_{2}$ tension. During short periods of asphyxia or hypoventilation the increase in arterial $\mathrm{CO}_{2}$ tension, and to a lesser extent the decrease in arterial $\mathrm{O}_{2}$ tension, would serve to cause cerebral vasodilation and thereby increase cerebral blood flow.

There are large numbers of commonly encountered clinical states which are associated with significant hypocapnia. It is striking that in almost all of these, signs of cerebral dysfunction are occasionally or frequently seen. These conditions include pulmonary congestion as a result of congestive heart failure (15), pulmonary infarction (16), pneumonia (17), alveolar capillary block (18), highly febrile states (19), certain acute cerebrovascular accidents (20), hepatic precoma and coma (21), intoxication with salicylates, dinitrophenol and sulfanilamide (22) and, most commonly, acute anxiety reactions (23). A relatively small change in pulmonary ventilation can produce significant lowering of arterial $\mathrm{CO}_{2}$ ten-

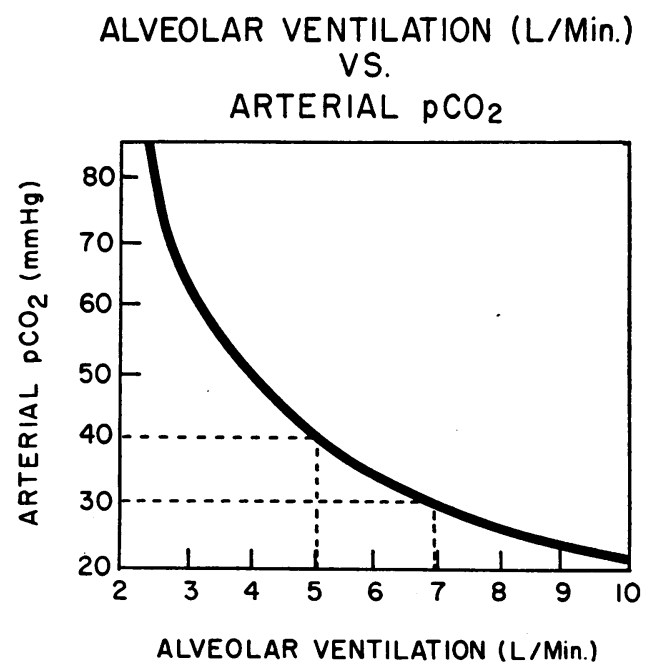

Fig. 3. EFFEct of Changes in alveolar ventilation ON ARTERIAL CARBon diOXIDE tension. Arterial $\mathrm{CO}_{\boldsymbol{z}}$ tension (ordinate) is plotted against alveolar ventilation (abscissa). Note that an increase in alveolar ventilation of $2 \mathrm{~L}$ per minute reduces arterial $\mathrm{P}_{\mathrm{CO}_{2}} 10 \mathrm{~mm} \mathrm{Hg}$ (replotted from Figure 14, Reference 24). sion. For example (Figure 3), increasing alveolar ventilation by only $2 \mathrm{~L}$ per minute will lower the arterial $\mathrm{CO}_{2}$ tension by $10 \mathrm{~mm} \mathrm{Hg}$. This in turn will induce sufficient cerebral vasoconstriction to reduce cerebral blood flow by 25 per cent. Such degrees of reduction in cerebral blood flow are associated with demonstrable deterioration in mental capacity. The potential danger of hyperventilation in aviation has been recognized (25) and studied (11). Balke and Lillehei (26) found that significant psychomotor impairment could be regularly produced by voluntary hyperventilation, and in some of their subjects marked impairment accompanied mild hypocapnia. In view of the demonstrated sensitivity of the cerebral vessels to hypocapnia, it is probable that the impairment in mental function is related, at least in part, to deficient cerebral blood flow. Recent animal studies have further stressed the importance of the hypoxia in brain tissue which accompanies hyperventilation, even with 100 per cent oxygen as the inspired gas $(27,28)$.

\section{SUM MARY}

The pattern of vasoconstrictor response of normal cerebral vessels to reduction in arterial car- . bon dioxide tension has been delineated.

The response of the cerebral vasculature to hypocapnia was in sharp contrast to the vasodilator response to hypercapnia. Following a $4.5 \mathrm{~mm}$ $\mathrm{Hg}$ increase in arterial $\mathrm{CO}_{2}$ tension required to initiate cerebral vasodilation, the increase in cerebral blood flow per unit increase in $\mathrm{CO}_{2}$ tension followed a curve which was steep and nearly linear.

Reduction in arterial $\mathrm{CO}_{2}$ tension beyond a small (approximately $2 \mathrm{~mm} \mathrm{Hg}$ ) threshold value initiated vasoconstriction. Further decrease in $\mathrm{CO}_{2}$ tension resulted in a progressively small reduction in cerebral blood flow per unit of $\mathrm{CO}_{2}$ change. The data suggest that a diminution of cerebral blood flow to 60 per cent of its control value is the approximate limit of the vasoconstrictor response to hypocapnia.

In the regulation of the cerebral circulation, the chemical control is based primarily on changes in end-capillary and venous blood gas tensions which occur secondary to changes in blood flow, which in turn are the result of changes in perfu- 
sion pressure. Calculations show that the vascular responses to $\mathrm{CO}_{2}$ would be initiated by a change in blood flow of approximately 30 per cent in either direction. Simultaneous changes in $\mathrm{O}_{2}$, tension probably increase the sensitivity of this chemical control mechanism.

\section{ACKNOWLEDGMENTS}

Grateful appreciation for technical assistance is expressed to Dr. H. Cohen, Dr. S. Cooke, Dr. M. Turner, Mrs. R. Dance, Mrs. A. Edwards, Mrs. P. Ewell, Miss T. Burton, Miss C. Carter and Miss B. Kriz.

\section{REFERENCES}

1. Kety, S. S., and Schmidt, C. F. The effects of altered arterial tensions of carbon dioxide and oxygen on cerebral blood flow and cerebral oxygen consumption of normal young men. J. clin. Invest. 1948, 27, 484.

2. Patterson, J. L., Jr., Heyman, A., Battey, L. L., and Ferguson, R. W. Threshold of response of the cerebral vessels of man to increase in blood carbon dioxide. J. clin. Invest. 1955, 34, 1857.

3. Kety, S. S., and Schmidt, C. F. The nitrous oxide method for the quantitative determination of cerebral blood flow in man: Theory, procedure and normal values. J. clin. Invest. 1948, 27, 476.

4. Patterson, J. L., Jr., Heyman, A., and Nichols, F. T., Jr. Cerebral blood flow and oxygen consumption in neurosyphilis. J. clin. Invest. 1950, 29, 1327.

5. Peters, J. P., and Van Slyke, D. D. Quantitative Clinical Chemistry, Methods. Baltimore, Williams and Wilkins, 1932, vol. 2.

6. Rosenthal, T. B. The effect of temperature on the $\mathrm{pH}$ of blood and plasma in vitro. J. biol. Chem. 1948, 173, 25.

7. Singer, R. B., and Hastings, A. B. An improved clinical method for the estimation of disturbances of the acid-base balance of human blood. Medicine (Baltimore) 1948, 27, 223.

8. Riley, R. L., Proemmel, D. D., and Franke, R. E. A direct method for determination of oxygen and carbon dioxide tensions in blood. J. biol. Chem. 1945, 161, 621.

9. Williams, E. J. Regression Analysis. New York, John Wiley \& Sons, 1959.

10. Finnerty, F. A., Jr., Witkin, L., and Fazekas, J. F. Cerebral hemodynamics during cerebral ischemia induced by acute hypotension. J. clin. Invest. 1954, 33, 1227.

11. Rahn, H., Otis, A. B., Hodge, M., Epstein, M. A., Hunter, S. W., and Fenn, W. O. Effects of hypocapnia on performance. J. Aviat. Med. 1946, 17, 164.

12. Schieve, J. F., and Wilson, W. P. The changes in cerebral vascular resistance of man in experi- mental alkalosis and acidosis. J. clin. Invest. 1953, 32, 33.

13. Sokoloff, L., Mangold, R., Wechsler, R. L., Kennedy, C., and Kety, S. S. The effect of mental arithmetic on cerebral circulation and metabolism. J. clin. Invest. 1955, 34, 1101.

14. Peters, J. P., and Van Slyke, D. D. Quantitative Clinical Chemistry, Interpretations. Baltimore, Williams and Wilkins, 1931, vol. 1.

15. Fraser, F. R., Harris, C. F., Hilton, R., and Linder, G. C. Arterial carbon dioxide pressure in cardiac dyspnoea. Quart. J. Med. 1928, 22, 1.

16. Robin, E. D., Julian, D. G., Travis, D. M., and Crump, C. H. A physiologic approach to the diagnosis of acute pulmonary embolism. New Engl. J. Med. 1959, 260, 586.

17. Herzog, H., Staub, H., and Richterich, R. Gasanalytical studies in severe pneumonia; observations during the 1957 influenza epidemic. Lancet 1959, 1, 593.

18. Austrian, R., McClement, J. H., Renzetti, A. D., Jr., Donald, K. W., Riley, R. L., and Cournand, A. Clinical and physiologic features of some types of pulmonary diseases with impairment of alveolarcapillary diffusion-The syndrome of "alveolarcapillary block." Amer. J. Med. 1951, 11, 667.

19. Graham, G., and Poulton, E. P. Influence of high temperature on protein metabolism with reference to fever. Quart. J. Med. 1912, 6, 82.

20. Plum, F., and Swanson, A. G. Central neurogenic hyperventilation in man. A. M. A. Arch. Neurol. Psychiat. 1959, 81, 535.

21. Tyor, M. P., and Sieker, H. O. Biochemical, blood gas and peripheral circulatory alterations in hepatic coma. Amer. J. Med. 1957, 27, 50.

22. Sollmann, T. H. A Manual of Pharmacology and its Applications to Therapeutics and Toxicology, 7th ed. Philadelphia, W. B. Saunders, 1948.

23. Gliebe, P. A., and Auerback, A. Sighing and other forms of hyperventilation simulating organic disease. J. nerv. ment. Dis. 1944, 99, 600.

24. Comroe, J. H., Jr., Forster, R. E., II., Dubois, A. B., Briscoe, W. A., and Carlsen, E. The Lung, Clinical Physiology and Pulmonary Function Tests. Chicago, Year Book Publishers, 1955.

25. Rushmer, R. F., Boothby, W. M., and Hinshaw, H. C. Some effects of hyperventilation with special reference to aviation medicine. Proc. Mayo Clin. 1941, 16, 801.

26. Balke, B., and Lillehei, J. P. Effect of hyperventilation on performance. J. appl. Physiol. 1956, 9, 371.

27. Sugioka, K., and Davis, D. A. Hyperventilation with oxygen-A possible cause of cerebral hypoxia. Anesthesiology 1960, 21, 135.

28. Meyer, J. S., and Gotoh, F. Metabolic and electroencephalographic effects of hyperventilation. A. M. A. Arch. Neurol. Psychiat. 1960, 3, 539. 